\title{
Predictors of poor maternal and perinatal outcome among singleton maternal delivery referral cases to the obstetrics unit of a tertiary health facility in Port Harcourt, Nigeria
}

\author{
Peter A. Awoyesuku*, Dagogo A. Mac Pepple
}

Department of Obstetrics and Gynaecology, Rivers State University Teaching Hospital, 6-8 Harley Street, Old G.R.A., Port-Harcourt, Nigeria

Received: 18 August 2019

Accepted: 30 September 2019

*Correspondence:

Dr. Peter A. Awoyesuku,

E-mail: pawoyesuku@yahoo.co.uk

Copyright: () the author(s), publisher and licensee Medip Academy. This is an open-access article distributed under the terms of the Creative Commons Attribution Non-Commercial License, which permits unrestricted non-commercial use, distribution, and reproduction in any medium, provided the original work is properly cited.

\begin{abstract}
Background: The high maternal and perinatal mortality rates in Nigeria continue to be issues of concern. That antenatal care improves both perinatal and maternal outcomes is now well established. The study seeks to identify the predictors of poor maternal and perinatal outcome among singleton maternal delivery cases referred to Rivers State University Teaching Hospital (RSUTH).

Methods: A longitudinal study was employed; the patients referred to RSUTH were followed up to ascertain maternal and neonatal outcomes. A sample size of 460 was used. Selection of cases was done by systematic sampling. Data obtained in the study were demographic, obstetric and perinatal findings. Maternal and perinatal outcome were dichotomized into poor and good outcomes. Bivariate and multivariate analyses were performed using SPSS version 20.0 .

Results: A total of 460 cases were recruited. The mean age \pm SD was $28.7 \pm 4.6$ years. There was poor maternal outcome in $65(14.1 \%)$ and poor perinatal outcome in $291(63.3 \%)$. There was one maternal death (rate $0.2 \%)$, perinatal mortality rate was $26.5 \%$, low birth-weight rate was $6.3 \%$ and asphyxia rate was $23.3 \%$. There is an association of multiparity and unbooked status with poor maternal outcome, while poor perinatal outcome was influenced by unbooked status.

Conclusions: Perinatal and maternal mortality were high amongst all referral cases. There is a positive correlation of multiparity with poor maternal outcome and between unbooked status and an increased risk of both maternal and perinatal adverse outcomes.
\end{abstract}

Keywords: Maternal outcome, Perinatal outcome, Predictors, Referral cases, Unbooked

\section{INTRODUCTION}

Maternal mortality has become a public health problem requiring urgent, concerted and effective intervention at the various levels of the society. ${ }^{1,2}$ In Nigeria, estimates of maternal mortality exceeds 1,000 per 100,000 live births. ${ }^{3,4}$ A study carried out by Nwobodo in NorthWestern Nigeria showed that obstetric emergencies were responsible for $96.7 \%$ and $87 \%$ of the maternal and perinatal mortality respectively. ${ }^{5}$

The high maternal and perinatal mortality rates in Nigeria continue to be issues of concern as they are indicators of the poor state of health services. That antenatal care improves both perinatal and maternal outcomes is now well established particularly for the more underprivileged segments of society. ${ }^{6-8}$ It is still recommended to 
electively refer high risk pregnant women for delivery before any complication arise to a healthcare center where all the facilities to deal with the complications are available and ready. The World Health Organization (WHO), in its Monitoring Indicators for Health Systems Handbook, defines availability as the "physical provision of health services" and readiness as "capacity to deliver health services".

Maternal and fetal outcomes in obstetric emergencies are adversely affected by lack of transport facilities, financial constraints due to poverty, illiteracy, ignorance, inadequate health infrastructure and meagre blood bank facilities. ${ }^{10,11}$ Delays at various levels, results in adverse outcome. Some studies in our environment had elucidated factors such as aversion to caesarean section and religious beliefs and cultural prejudices as barriers hindering women from utilizing antenatal care and hospital delivery. ${ }^{12,13}$

In light of the high maternal and perinatal morbidity and mortality associated with unbooked cases in Nigeria, it is pertinent to determine and conceptualize the relationship between sociodemographic characteristics of unbooked mothers, with a view to determine the correlation with maternal and perinatal outcomes. The findings from such studies have implications for planning and implementing interventions that are relevant for maternal and perinatal mortality reduction. The study aimed at comparing the socio-demographic characteristics of referral singleton maternal delivery cases as predictors of poor maternal and perinatal outcomes.

\section{METHODS}

A prospective descriptive study was carried out. The study population was made up of patients referred to the RSUTH, either from the peripheral hospitals or selfreferred, for delivery during the study period. The study was carried out over a ten-month period, from April to December 2017. The study was carried out at the maternity unit of the RSUTH. The RSUTH is one of two tertiary hospital for referral from all private clinics, maternity homes, primary health centers and secondary health facilities from all the 23 local government areas of Rivers State, Nigeria. The hospital is funded by the government and patients are expected to pay directly for services (except few that participate in National Health Insurance Scheme).

It provides emergency obstetric services to women referred from other centers, as well as providing antenatal care and delivery services for low and high-risk pregnant women booked with the hospital.

The hospital is well equipped and has round the clock availability of qualified team comprising of obstetricians, pediatricians and anaesthetist. There is availability of laboratory and blood bank services in the hospital.
Using the formula, $n=\frac{(Z \alpha+Z \beta)^{2}(p q)}{(e)^{2}}$ where $\mathrm{n}$ is the minimum sample size; ' $\mathrm{Z} \alpha$ ' is the standard normal deviate of 1.96; ' $Z \beta$ ' is the power of study set at $80 \%$ which corresponds to 0.84 ; ' $p$ ' is proportion of referral cases for obstetric care at a tertiary health facility from a similar study $(17.83 \%$ was reported by Sabale and Patankar; 'e' is the tolerable error limit set at 5\% (0.05), a sample size of 460 was obtained. ${ }^{14,15}$

All referred antepartum and intrapartum singleton cases to our labour ward, 20 weeks gestation and above, were eligible for inclusion; while cases $<20$ weeks gestation, booked cases at our centre, referred multiple pregnancy cases and postpartum referral cases were excluded from the study. Selection of cases was done by systematic sampling technique; alternate eligible cases were recruited.

Data was obtained through structured proforma by trained resident doctors who acted as research assistants. The socio-demographic characteristics of each patient was entered into a proforma on entering the study, and they were followed up until delivery and discharge home, to ascertain maternal and perinatal outcomes. Maternal outcome of referral obstetric cases was dichotomized into poor and good outcomes. Poor maternal outcome comprised of maternal complications such as anemia, sepsis, wound break down, cervical tear, puerperal depression, retinopathy and mortality. perinatal outcomes were categorized as poor and good. The presence of any fetal morbidity / mortality comprised a poor outcome.

Bivariate and multivariate analyses were performed using the Statistical Package for Social Sciences (SPSS) version 20.0. Pearson's Chi square was used in the bivariate analysis while multivariate analysis employed logistic regression to identify predictors of poor outcome. Statistical significance was set at $\mathrm{P}<0.05$. Only significant variables on bivariate analysis were included in the logistic regression analysis. Confidence intervals were calculated at the $95 \%$ level.

\section{RESULTS}

A total of 460 referral obstetric cases were included in the study. The mean age $\pm \mathrm{SD}=28.7 \pm 4.6$ years; minimum and maximum ages were 15 and 45 years respectively. Of the 460 referred cases, $395(85.9 \%)$ mothers had good outcome without complications, while 65 (14.1\%) had poor outcome. The commonest complications observed among the referred cases were anaemia 51 (11.1\%), sepsis/wound infection $8(1.7 \%)$ and cervical tear 3 $(0.7 \%)$.

Figure 1, 2. One maternal death of the 460 referral cases $(0.2 \%)$ giving a maternal mortality ratio of 217 per 100,000 live births. This mortality was a non-obstetrical emergency (upper GI bleeding) who came in moribund and died shortly after. 
Table 1: Factors associated with maternal outcome (bivariate analysis).

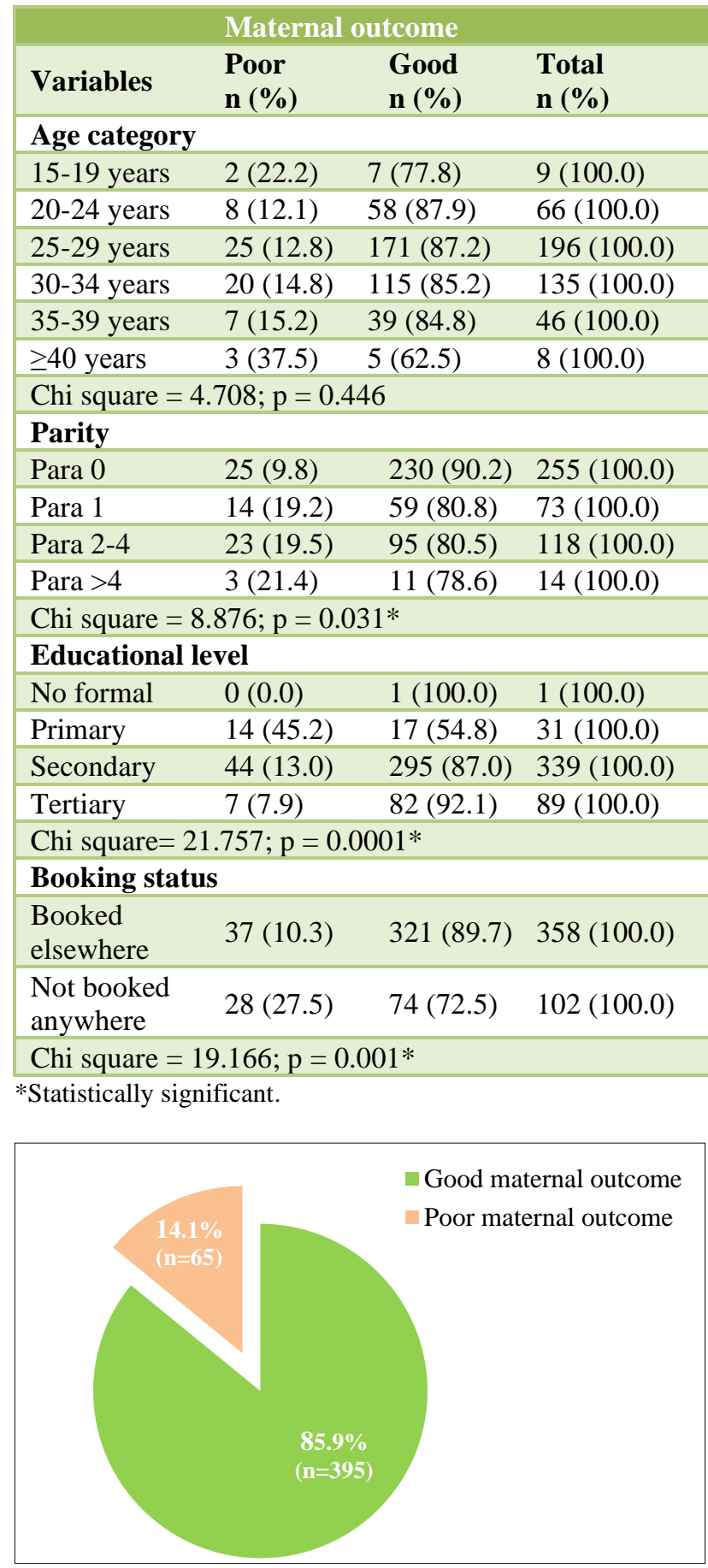

Figure 1: Distribution of maternal outcomes (poor/good) among obstetric referral cases $(\mathrm{N}=460)$.

Among the 460 delivery cases, majority, 291 (63.3\%), had poor perinatal outcome; while 169 (36.7\%) had good outcome. The 291 poor outcome consists of birth asphyxia (Apgar score <7) 107 (36.8\%), low birth weight $(<2500 \mathrm{~g}) 29(10.0 \%)$ and macrosomia in $33(11.3 \%)$, all of whom were admitted for care at the Special Care Baby Unit (SCBU); giving the proportion of babies admitted to SCBU as $36.7 \%$. Other poor outcomes were fresh stillborn $83(28.5 \%)$, macerated stillborn/IUFD 31 (10.6\%) and immediate neonatal death 8 (2.8\%). See Figure 3, 4. Of the 460 referral cases, that gives a perinatal mortality rate of $26.5 \%$ (Ratio of 265 per 1,000 live births), low birth-weight rate of $6.3 \%$ and asphyxia rate of $23.3 \%$.

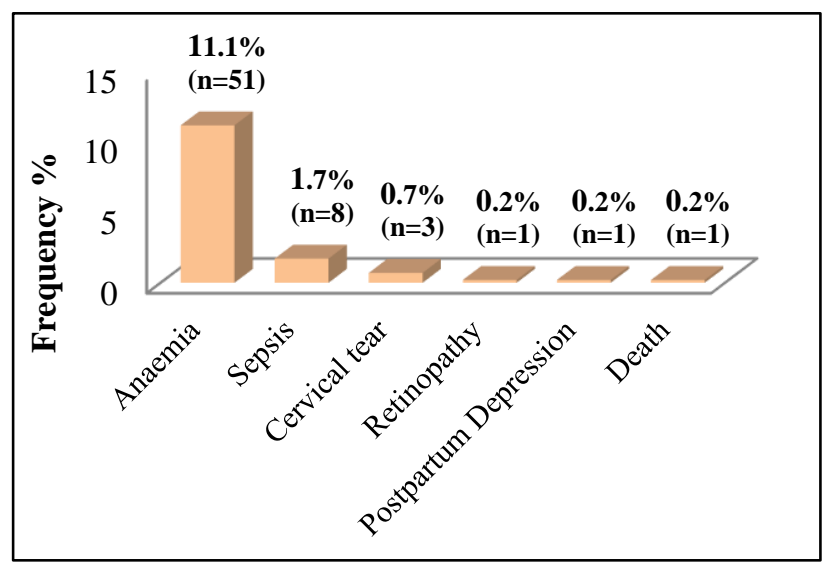

Figure 2: Distribution of maternal complications among obstetric referral cases $(\mathrm{N}=65)(\%$ of 460 referred cases).

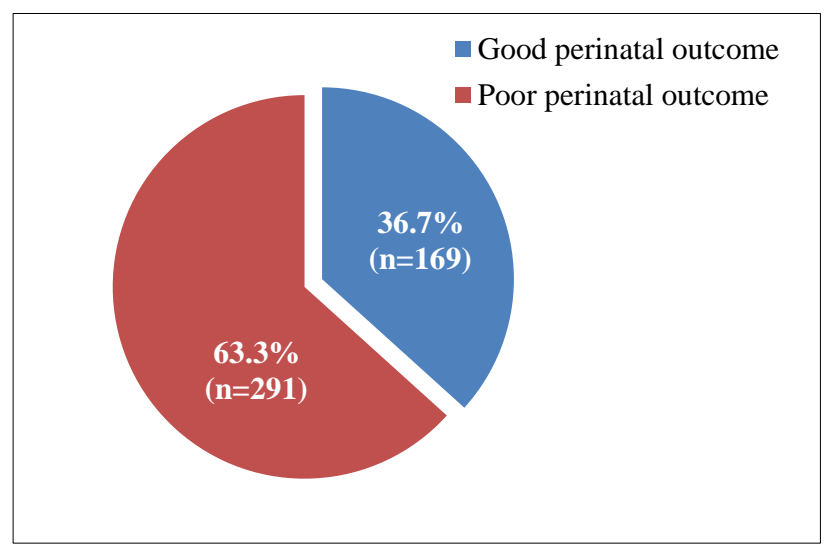

Figure 3: Distribution of perinatal outcome among births of obstetric referral cases $(\mathrm{N}=460)$.

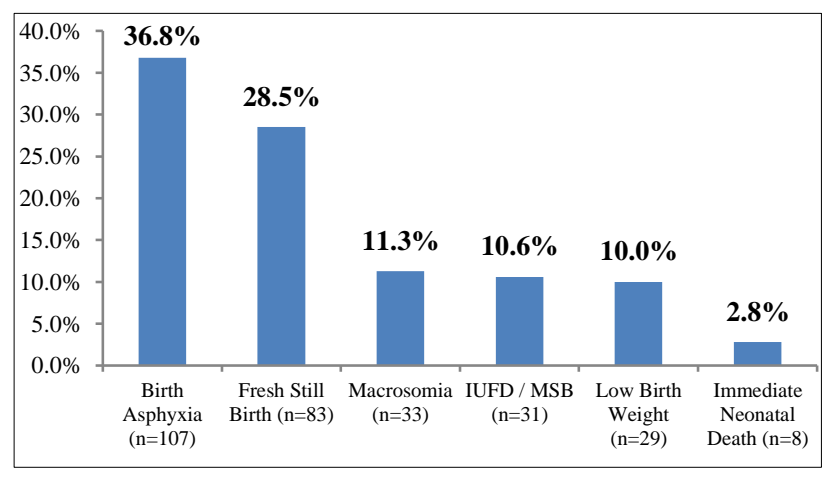

Figure 4: Distribution of fetal outcomes among obstetric referral cases $(\mathrm{N}=291)$.

Bivariate analysis of sociodemographic factors associated with poor maternal outcome (Table 1) showed a 
significant association with only parity, educational status and booking status as predictors.

Table 2: Logistic regression of factors associated with poor maternal outcome.

\section{5\% Confidence interval}

\begin{tabular}{|c|c|c|c|c|}
\hline Factors & $\begin{array}{l}\text { Odds ratio } \\
\text { (OR) }\end{array}$ & $\begin{array}{l}\text { Lower } \\
\text { limit }\end{array}$ & $\begin{array}{l}\text { Upper } \\
\text { limit }\end{array}$ & $\begin{array}{l}p \text { - } \\
\text { value }\end{array}$ \\
\hline \multicolumn{5}{|c|}{ Educational level } \\
\hline $\begin{array}{l}\text { Below tertiary } \\
\text { level }\end{array}$ & 1.69 & 0.73 & 3.93 & 0.224 \\
\hline Tertiary level & 1 & 1 & 1 & \\
\hline \multicolumn{5}{|l|}{ Parity } \\
\hline $\begin{array}{l}\text { >Para-0 } \\
\text { (multiparous) }\end{array}$ & 2.11 & 1.22 & 3.66 & $0.008 *$ \\
\hline $\begin{array}{l}\text { Para-0 } \\
\text { (nulliparous) }\end{array}$ & 1 & 1 & 1 & \\
\hline \multicolumn{5}{|l|}{ Booking status } \\
\hline $\begin{array}{l}\text { Not booked } \\
\text { anywhere }\end{array}$ & 2.94 & 1.67 & 5.19 & $0.0001 *$ \\
\hline $\begin{array}{l}\text { Booked } \\
\text { elsewhere }\end{array}$ & 1 & 1 & 1 & \\
\hline
\end{tabular}

Table 3: Factors associated with perinatal outcome (bivariate analysis).

\begin{tabular}{|c|c|c|c|}
\hline \multicolumn{4}{|c|}{ Perinatal outcome } \\
\hline Variables & $\begin{array}{l}\text { Poor } \\
\text { n }(\%)\end{array}$ & $\begin{array}{l}\text { Good } \\
\text { n (\%) }\end{array}$ & $\begin{array}{l}\text { Total } \\
\text { n }(\%)\end{array}$ \\
\hline \multicolumn{4}{|l|}{ Age category } \\
\hline $15-19$ years & $6(66.7)$ & $3(33.3)$ & $9(100.0)$ \\
\hline $20-24$ years & $41(62.1)$ & $25(37.9)$ & $66(100.0)$ \\
\hline $25-29$ years & $127(64.8)$ & $69(35.2)$ & $196(100.0)$ \\
\hline $30-34$ years & $83(61.5)$ & $52(38.5)$ & $135(100.0)$ \\
\hline 35 - 39 years & $26(56.5)$ & $20(43.5)$ & $46(100.0)$ \\
\hline$\geq 40$ years & $8(100.0)$ & $0(0.0)$ & $8(100.0)$ \\
\hline \multicolumn{4}{|c|}{ Fisher's exact $=6.326 ; p=0.273$} \\
\hline \multicolumn{4}{|l|}{ Parity } \\
\hline Para 0 & $153(60.0)$ & $102(40.0)$ & $255(100.0)$ \\
\hline Para 1 & $48(65.8)$ & $25(34.2)$ & $73(100.0)$ \\
\hline Para 2 - 4 & $80(67.8)$ & $38(32.2)$ & $118(100.0)$ \\
\hline Para $>4$ & $10(71.4)$ & $4(28.6)$ & $14(100.0)$ \\
\hline \multicolumn{4}{|c|}{ Chi Square $=2.808 ; p=0.422$} \\
\hline \multicolumn{4}{|c|}{ Educational level } \\
\hline No formal & $0(0.0)$ & $1(100.0)$ & $1(100.0)$ \\
\hline Primary & $26(83.9)$ & $5(16.1)$ & $31(100.0)$ \\
\hline Secondary & $208(61.4)$ & $131(38.6)$ & $339(100.0)$ \\
\hline Tertiary & $57(64.0)$ & $32(36.0)$ & $89(100.0)$ \\
\hline \multicolumn{4}{|c|}{ Fisher's Exact $=8.116 ; p=0.027^{*}$} \\
\hline \multicolumn{4}{|c|}{ Booking status } \\
\hline $\begin{array}{l}\text { Booked } \\
\text { elsewhere }\end{array}$ & $216(60.3)$ & $142(39.7)$ & $358(100.0)$ \\
\hline $\begin{array}{l}\text { Not booked } \\
\text { anywhere }\end{array}$ & $75(73.5)$ & $27(26.5)$ & $102(100.0)$ \\
\hline Chi square $=$ & $6 ; p=0$. & & \\
\hline
\end{tabular}

*Statistically significant.
However, following multivariate analysis only parity and booking status remain significant (Table 2). Multiparous women were twice more likely to have poor maternal outcome than nulliparous women (Odds ratio $=2.11$; 95\% CI: 1.22-3.66), while unbooked women were about 2.9 times more likely to experience poor maternal outcomes in comparison to those booked elsewhere (had some form of antenatal care at referral hospital) (odds ratio $=2.94 ; 95 \% \mathrm{CI}: 1.67-5.19$ )

Bivariate analysis of socio-demographic factors associated with poor perinatal outcome (Table 3) showed a significant association with only educational status and booking status as predictors. However, following multivariate analysis only booking status remained significant (Table 4).

Table 4: Logistic regression of factors associated with poor perinatal outcome.

\begin{tabular}{|lllll|}
\hline \multicolumn{5}{|c|}{$95 \%$ Confidence interval } \\
\hline Factors & $\begin{array}{l}\text { Odd ratio } \\
\text { (OR) }\end{array}$ & $\begin{array}{l}\text { Lower } \\
\text { limit }\end{array}$ & $\begin{array}{l}\text { Upper } \\
\text { limit }\end{array}$ & p-value \\
\hline Educational level & & & \\
\hline $\begin{array}{l}\text { Below tertiary } \\
\text { level }\end{array}$ & 0.86 & 0.53 & 1.41 & 0.557 \\
\hline Tertiary level & 1 & 1 & 1 & \\
\hline Booking status & & & \\
\hline $\begin{array}{l}\text { Not booked } \\
\text { anywhere }\end{array}$ & 1.87 & 1.14 & 3.07 & $\begin{array}{l}* \\
*\end{array}$ \\
\hline $\begin{array}{l}\text { Booked } \\
\text { elsewhere }\end{array}$ & 1 & 1 & 1 & \\
\hline
\end{tabular}

*Statistically significant.

Unbooked women were about twice more likely to experience poor perinatal outcomes in comparison to those booked elsewhere (odds ratio $=1.87 ; 95 \%$ CI: 1.14 - 3.07).

\section{DISCUSSION}

The study has shown that referral cases or unbooked obstetric emergencies are associated with high maternal and perinatal morbidity and mortality. The maternal mortality rate of $0.2 \%$ ( 217 per 100,000 live births) is on the high side. However, Sabale et al, and Owolabi et al, reported a maternal mortality rate of $0.8 \%$ and $3.8 \%$ in their respective studies, which are higher than ours. ${ }^{15,16}$ This may be attributable to differences in response time and the availability and readiness of healthcare services in the different centers.

The perinatal mortality rate of $26.5 \%$ (ratio of 265 per 1,000 live births) is also high, and comparable to the findings of $32.5 \%$ reported by Owolabi et al. ${ }^{16}$ However, several other studies have reported lower stillborn rates such as Sabale et al, (10.2\%), Khatoon et al (13\%) and Blondel et al, (4.7\%). ${ }^{15,17,18}$ These studies were carried out in India, Pakistan and France respectively. The higher 
perinatal mortality in the study and Owolabi et al, both carried out in Nigeria, may be due to the fact that some of the unbooked patients may have been admitted in labour in substandard peripheral facilities only to be referred to the university hospital after a prolonged delay and onset of complications. ${ }^{16}$ High risk pregnancy identification and its timely referral to higher centers with facilities for specialist care holds the key to success in reducing the high fetal wastages associated with unbooked emergencies.

Admission for neonatal intensive care in our SCBU was also high at $36.7 \%$. This is similar to the findings by Blondel et al (33.3\%) and Charu et al, (56.2\%), but unlike their findings that majority of their reasons for admission was low birth weight from prematurity, $22.3 \%$ and $56 \%$ respectively, majority of the reason for admission was birth asphyxia $(23.3 \% \%)$ rather than low birth weight $(6.3 \% \%){ }^{18,19}$ Sabale et al had a lower admission rate in their study, but also due mainly to low birth weight from prematurity $(54.9 \%)$, than birth asphyxia $(9.8 \%) .{ }^{15}$ The same extreme delay before referral, when the fetuses are almost moribund, may explain the very high birth asphyxia rate in the study.

Parity and unbooked status were statistically significant correlates (and therefore predictors) of poor maternal outcome. Multiparous women were twice more likely to have poor maternal outcome than nulliparous women, while unbooked women were about 2.9 times more likely to experience poor maternal outcomes in comparison to those booked elsewhere. This is similar to the findings by Owolabi et at, who also reported correlation between parity and unbooked status and poor maternal outcome. Lower educational level, significantly associated with poor maternal outcome on bivariate analysis, was not significant on logistic regression testing. ${ }^{16}$

Unbooked women were about twice more likely to experience poor perinatal outcomes in comparison to those booked elsewhere in the study. ${ }^{16}$ Owolabi et al, also found a strong correlation between booking status and poor perinatal outcome. But unlike their study, parity was not associated with poor perinatal outcome in the study. Like for poor maternal outcome, lower educational level, significantly associated with poor perinatal outcome on bivariate analysis, was not significant on logistic regression testing.

\section{CONCLUSION}

Perinatal and maternal mortality were high amongst our referral cases. There was a positive correlation of multiparity with poor maternal outcome and between unbooked status and an increased risk of both maternal and perinatal adverse outcomes. Efforts should be made to identifying the women most likely to have no antenatal care, and ensuring that existing health services are available for them.
Maternal education and socioeconomic status are important determinants of use of antenatal care. Reduction in poverty and female illiteracy, and improvement in health awareness or health seeking behavior as well as status of women in our societies, will help in making pregnancy safe.

\section{ACKNOWLEDGMENTS}

Authors would like to thank the interns and resident doctors who voluntarily assisted in the recruitment of cases by systematic sampling and follow up of the mothers to ascertain maternal and perinatal outcomes.

\section{Funding: No funding sources \\ Conflict of interest: None declared \\ Ethical approval: Not required}

\section{REFERENCES}

1. Hill K, Abouzahr C, Wardlaw T. Estimates of maternal mortality for 1995. Bulletin World Health Organization. 2001;3:182-93.

2. Buckens P. Is estimating maternal mortality useful? Bulletin World Health Organization. 2001;79:3.

3. Fasubaa OB, Oguniyi SO, Ezechi OC. Maternal mortality in Obafemi Awolowo University Teaching Hospital Complex Ile-Ife - a compares of maternal death in young and older women. Nig $\mathrm{J}$ Med. 2000:4;147-51.

4. Okonta PI, Okali UK. Otoide VO, Twomey D. Exploring the causes of and risk factors for maternal deaths in a rural Nigerian referral hospital. J Obstete Gynaecol. 2002;22:626-9.

5. Nwobodo EL. Obstetric emergencies as seen in a tertiary health institution in North-Western Nigeria: maternal and foetal outcome. Nigerian Medical Practitioner. 2006;49:54-5.

6. Ekwempu CC. The influence of antenatal care on pregnancy outcome. Trop J Obstet Gynaecol. 1988;1:67-71.

7. Greenberg R. The impact of prenatal care in different social groups. Am J Obstet Gynecol. 1983;145:797801.

8. Conde A, Belizan JM, Diaz JL. Epidemiology of fetal death in Latin America. Acta Obstet Gynecol Scand. 2000;79:371-8.

9. World Health Organization. Monitoring the building blocks of health systems: a handbook of indicators and their measurement strategies. Geneva: WHO; 2010. Available at: https:// www. who. int/ healthinfo/ systems/WHO_MBHSS_2010_full_ web.pdf. Accessed on 10 August 2019.

10. Drife J. Maternal mortality. In: Lueslay DM, Baker PN. Obstetrics and Gynaecology and EvidenceBased Text for MRCOG. $1^{\text {st }}$ edition. Arnold Publishers; 2004:196-204.

11. Chukwudebelu WO. Preventing maternal mortality in developing countries, In: Okonofua A, Odunsi K, editors. Contemporary Obstetrics and Gynaecology 
for Developing Countries. Women's Health Act Res Centre. 2003:644-657.

12. Ukpong DI, Owolabi AT. Psychiatric morbidity associated with caesarean section: a study from Wesley Guild Hospital, Ilesa. Nigeria J Obste Gynaecol. 2004;28:891-4.

13. Etuk SJ, Etuk IS, Ekott MI, Udoma EJ. Perinatal outcome in pregnancies booked for antenatal care but delivered outside health facilities in Calabar, Nigeria. Acta Trop. 2000;24:745-9.

14. Katz DL, Wild DMG, Elmore JG, Lucan SC. Sample size calculation for epidemiological studies. Jekel's Epidemiology, Biostatistics, Preventive Medicine and Public Health. $4^{\text {th }}$ ed. Philadelphia: Saunders / Elsevier. 2014:155.

15. Sabale U, Patankar AM. Study of maternal and perinatal outcome in referred obstetrics cases. J Evolution Med Dental Sci. 2015;4:4448-55.

16. Owolabi AT, Fatusi AO, Kuti O, Adeyemi A, Faturosi SO, Obiajuwa PO. Maternal complications and perinatal outcomes in booked and unbooked Nigerian mothers. Singapore Med J. 2008;49:526-31.

17. Khatoon A, Hasny SF, Irshad S, Ansari J. An audit of obstetrics referral to Abbasi Shaheed Hospital. Pak J Surg. 2011;27:304-8.

18. Blondel B, Dutilh P, Delour M, Uzan S. Poor antenatal care and pregnancy outcome. European $\mathbf{J}$ Obst Gynecol Reprod Biol. 1993;50:191-6.

19. Charu R, Kamal G, Neelu S. Review of referred obstetric cases: maternal and perinatal outcome. Bombay Hosp J. 2010;52:1.

Cite this article as: Awoyesuku PA, Mac Pepple DA. Predictors of poor maternal and perinatal outcome among singleton maternal delivery referral cases to the obstetrics unit of a tertiary health facility in Port Harcourt, Nigeria. Int J Reprod Contracept Obstet Gynecol 2019;8:4479-84. 